\title{
A Report from the International Federation of Societies for Surgery of the Hand: from the Committee on Spinal Cord Injuries 1980
}

\author{
Committee members: ERIK Moberg (Sweden), Chairman; Alvin A. Freehafer \\ (U.S.A.); Douglas W. Lamb (U.K.); Robert D. LefFert (U.S.A.); HenRy NigST
} (Switzerland) and EdUARDo A. Zancolli (Argentina).

RECENT advances have clearly shown (see References) that the continued prevailing negative attitude towards arm and hand surgery as a way to improve function in tetraplegia from spinal cord injury is no longer justified. This point of view was stressed by all the members of the International Group Conference in Edinburgh in 1978 (McDowell et al., I979; Moberg \& Nigst, I979; Moberg \& Lamb, I980). But the field has to be approached with great care and knowledge. New ways of thinking, different from the concepts routinely used in everyday hand surgery, are required. Under such circumstances the risk of further loss is almost non-existent, especially if reversible procedures are used whenever possible.

The old classification built upon neurological levels, for example C5-C6 etc., is too crude for this field. Every arm must be classified separately (Moberg, I975 and 1978; Lamb, 1979; McDowell et al., 1979). The classification must include and, according to most workers in the field, be built upon the presence or absence of afferent impulses, either from vision, from cutaneous sensibility or from both. Two-point discrimination is used, as the ordinary sensory modalities are not reliable as a base for classification for surgery. In addition, available muscles below the elbow, including the brachioradialis, which have enough power to be used as transfers will complete the classification. The triceps muscle must also be evaluated and included. Types of classifications are given as examples in the references below.

It is generally agreed that a classification must be used which will explain to the readers of papers exactly the loss and what has been left.

It is clear that important differences exist between groups of patients coming for surgery in different countries; more high cases in the U.S.A. and in Scandinavia, lower cases in Argentina and Australia, and in Scotland between these levels.

Reconstructive surgery in this field is now firmly established in Argentina, Finland, Scotland, Spain, Sweden, Switzerland and the U.S.A.

The procedures in question can be applied mainly in order to obtain:

(I) active elbow extension

(2) a more or less complete active hand grip, or

(3) to eliminate disturbing localised upper limb spasticity.

Spasticity may be at times useful.

I. Active elbow extension has been greatly appreciated also when given to patients in whom no active hand grip could be obtained and also when it could not improve their ability to transfer. Such patients have found their range of motion improved; they had better arm control, especially in bed; and they could drive a car with less difficulty and risk. The construction of an active elbow extensor 
improves the possibility to use the brachioradialis as a transfer, as this requires an active antagonist to achieve sufficient power.

Active elbow extension is obtained by a transfer of the posterior part of the deltoid to the triceps tendon (Moberg, I975) bridging the gap by free toe tendon grafts. Another method to bridge the gap (Pitá \& Castro, personal communication) by a reflected strip of the triceps tendon seems able to shorten the long period of immobilisation and education so far necessary. In some cases (Zancolli, I979) the biceps has been used as a transfer for the same purpose, but this requires the presence of a good supinator.

2. The hand grip construction (it is much more the question of construction than of reconstruction) should, with very few exceptions in low tetraplegia cases, never aim at an imitation of the normal hand function. It is much more the question of a concentration of all resources left, sensory and motor, in one single useful action. Only in the few better cases will it be the question of obtaining two or three actions.

There has been a general agreement on the importance of sensibility as a source of afferents for the motor 'feedback'. Vision as the only source of afferents is much inferior. There has been discussion if it is useful to give both hands a grip in cases where only visual control is present (Lamb \& Landry, 1972). The loss must be evaluated in detail for each hand, sensory as well as motor function. Experiences with hand reconstruction in polio (with normal sensibility), has often been misleading in tetraplegia, where loss of tactile gnosis as well as proprioception is common, the latter often the cause of late contractures.

Thumb opposition should not be aimed at since the key grip with its better power and broader surface is preferable, especially as it requires much less motor function. For human contact and for transfer function the tetraplegic hand should be kept supple and pliable; joint fusions should be avoided as much as possible. The flexor carpi radialis muscle should not be used as a transfer. There is a general agreement today that it is more valuable for its own function. Also active wrist extension should be regarded as the best basis for grip construction. Accordingly, the wrist should not be fused to obtain more musculotendinous units for transfer. The extensor carpi radialis brevis has the right position as a wrist extensor but is not always strong enough. Therefore, before using the longus as a transfer, the brevis must be tested in open surgery as closed evaluation is not reliable.

Active or activated flexors can easily produce late contractures, especially in digits lacking proprioception. The risk for such late contractures should be noted much more than it is now; above all, in cases where flexor construction without antagonistic extensors is contemplated.

3. When localised spasticity is a detriment promising results have been obtained by denervation. In such cases local blocking should be performed several times and the patient allowed to test the anticipated result preoperatively. However, observations in this field are still too few to permit conclusions or to elaborate on indications.

Just as all aspects of the surgery in this field require a slowly and cautiously accumulated experience, so must the very important occupational therapy and physiotherapy before and after surgery be very different from 'routine' therapy. The rotation system for therapists is incompatible with good care for these patients. Continuity is a must in all aspects of this field, where each case is a special problem. So many other problems are involved in the treatment of tetraplegia. The arm and hand problems should of course be considered from the very early stage with train- 
ing and splinting, but the surgery itself is rarely considered until about a year after the accident. But even beyond 15 years after their injury, patients are asking for the improvement that they have seen in other tetraplegics who have had operations on the upper limb.

The field of surgical rehabilitation of the upper limb in tetraplegia is now in an advancing stage and further progress is to be expected.

\section{ERIK MOBERG \\ Göteborg, \\ Sweden}

\section{REFERENCES}

BRYAN, R. S. (1977). The Moberg deltoid-triceps replacement and key-pinch operations in quadriplegia. Preliminary experiences. The Hand, 9, 207-214.

DeBENEDETTI, M. (1979). Restoration of elbow extension power in the tetraplegic patient using the Moberg technique. F. of Hand Surg., 4, 86-89.

FreehAFER, A. A., VonhaAm, E. \& Allen, V. (I974). Tendon transfers to improve grasp after injuries of the cervical spinal cord. F. Bone foint Surg., 56A, 95I-959.

FreeHAFER, A. A. (1977-78). Flexion and supination deformities of the elbow in tetraplegics. Paraplegia, 15, 221-225.

FreeHAFER, A. A. (1979). Determination of muscle-tendon unit properties during tendon transfer. F. of Hand Surg., 4, 33 I-339.

Hentz, V. R. \& KeOSHian, L. A. (I979). Changing perspectives in surgical hand rehabilitation in quadriplegic patients. Plast. and Reconstruct. Surg., 64, 509-515.

House, J. H., GWATHMEY, F. W. \& LunDSGAARD, D. K. (1976). Restoration of strong grasp and lateral pinch in tetraplegia due to spinal cord injury. F. of Hand Surg., I, I 52-I59.

LAMB, D. W. \& LANDry, R. M. (1972). The hand in tetraplegia. Paraplegia, 9, 204.

LAMB, D. W. (1979). Current situation in the management of the upper limb in tetraplegia. Rehab. Medicine, $\mathbf{r}$.

McDowell, C. L., Moberg, E. \& SMith, A. G. (1979). International conference on surgical rehabilitation of the upper limb in tetraplegia. F. of Hand Surg., 4, 387-390.

MoBerg, E. (1977). Editorial. The Hand, 9, 205-206.

MoBeRG, E. (1978). The upper limb in tetraplegia. A new approach to surgical rehabilitation. Thieme, Stuttgart.

MoBERG, E. \& LAMB, D. W. (I980). Surgical rehabilitation of the upper limb in tetraplegia. Proceedings of the international conference in Edinburgh. The Hand, 12, 209-213.

Moberg, E. \& Nigst, H. (1979). Kongressbericht. Internationale Arbeitstagung in Edinburgh über chirurgische Rehabilitation der oberen Extremitätren det Tetraplegiken. Handchirurgie, II, 255-257.

Pitá, L. \& Castro, A. (Personal communication). A new surgical technique to correct triceps paralysis.

SMITH, A. G. (I98I). Early complications of key grip hand surgery for quadriplegia. Paraplegia, 19, I23-126.

ZANCOLLI, E. (I979). Functional restoration of the upper limbs in traumatic quadriplegia 229-262. In Zancolli: Structural and dynamic basis of hand surgery. 2nd Edition. J. B. Lippincott Company, Philadelphia. 